\title{
A Atenção Primária sob a ótica dos usuários do Sistema Único de Saúde: uma revisão bibliográfica
}

\author{
Aurélio Carlos Silva da Silva \\ Acadêmico do Curso de Bacharel em Enfermagem \\ Faculdade Estácio de Macapá, Brasil \\ 凶aurelio-mcp@hotmail.com \\ Ismael Robson Batista Soares \\ Acadêmico do Curso de Bacharel em Enfermagem \\ Faculdade Estácio de Macapá, Brasil \\ 凶ismael_skymake_@outlook.com \\ Kliger Fabiano Costa Campos \\ Acadêmico do Curso de Bacharel em Enfermagem \\ Faculdade Estácio de Macapá, Brasil \\ 凶k kligercampos@gmail.com \\ Mônica Cristina da Silva Castro \\ Licenciatura Plena e Bacharel em Enfermagem pela Universidade Federal do Amapá \\ Especialista em Unidade de Terapia Intensiva. Mestre em Saúde da Família. \\ Docente na Faculdade Estácio de Macapá no Curso de Enfermagem. \\ $凶 \underline{\text { monica.cristinacastro@hotmail.com }}$
}

Recebido em 21 de agosto de 2019

Aceito em18 de setembro de 2019

\section{Resumo:}

A atenção primária à saúde é o primeiro nível de contato dos indivíduos, da família e da comunidade com o sistema nacional de saúde. O estudo analisou a produção científica sobre a atenção primária sob a ótica dos usuários do Sistema Único de Saúde, por meio da literatura científica, ao identificar as potencialidades e fragilidades do atendimento ao usuário do sistema único de saúde. Trata-se de uma pesquisa bibliográfica. Foram realizadas buscas em bancos de dados, sendo acessadas por via portal da Biblioteca Virtual da Saúde (BVS) como Literatura Latino-Americana em Ciências da Saúde, Scientific Eletronic Library Online e Base de Dados da Enfermagem, em artigos disponíveis na íntegra, em idioma Português-BR, publicados no período de 2013 a 2017. Na análise dos dados emergiram três categorias temáticas, sendo apresentadas nos resultados: "as potencialidades evidenciadas pelos usuários do Sistema Único de Saúde frente ao atendimento na rede básica de saúde"; "as fragilidades relacionadas ao atendimento dos usuários aos serviços de saúde no âmbito da atenção primária" e a "importância da atenção primária enquanto porta de entrada dos usuários na rede dos serviços de saúde". Têm-se como resultado, segundo a percepção de usuários, que a atenção primária é considerada incipiente e um grande desafio para gestores. Conclui-se que é importante empreender uma discussão mais sólida sobre as diferentes formas de acesso aos usuários da atenção primária à saúde e também vislumbrar ações de melhoria tanto no planejamento quanto nas relações entre todos os integrantes da equipe de saúde e dos usuários que buscam atendimento no sistema único de saúde, para que o princípio da integralidade seja de fato vislumbrado.

Palavras-chave: Atenção Primária à Saúde, Comportamento do Consumidor, Sistema Único de Saúde. 


\title{
Primary Care from the perspective of the users of the Unified Health System: a bibliographic review
}

\begin{abstract}
:
Primary health care is the first level of contact between individuals, the family and the community with the national health system. The study analyzed the scientific production on primary care from the perspective of the users of the single health system, through scientific literature, when identifying the potentialities and fragilities before the single health system user care. It is a bibliographical research. Searches were carried out in databases, being accessed through a portal of the Virtual Health Library such as Latin American Literature in Health Sciences, Scientific Electronic Library Online and data base nursing), in articles available in full, in Portuguese-BR, published between 2013 and 2017. In the analysis of the data, three thematic categories emerged, being presented in the results: "the potentialities evidenced by users of the Unified Health System care in the basic health network "; "the frailties related to the care of users to health services in primary care" and "the importance of primary care as a gateway for users in the health services network." As a result, according to the perception of users, primary care is considered incipient and a great challenge for managers. It is concluded that is important to undertake a more solid discussion about the different forms of access to primary health care users and also to envisage improvement actions both in planning and in the relationships between all members of the health team and users seeking care in the single health system, so that the principle of completeness is actually glimpsed.
\end{abstract}

Keywords: Primary Health Care, User Behavior, Single Health System.

\section{La Atención Primaria bajo la óptica de los usuarios del Sistema Único de Salud: una revisión bibliográfica}

\begin{abstract}
Resumen:
La atención primaria a la salud es el primer nivel de contacto de los individuos, de la familia y de la comunidad con el sistema nacional de salud. El estudio analizó la producción científica sobre la atención primaria bajo la óptica de los usuarios del Sistema Único de Salud, a través de la literatura científica, al identificar las potencialidades y fragilidades de la atención al usuario del sistema único de salud. Se trata de una investigación bibliográfica. Se realizaron búsquedas en bancos de datos, siendo accedidas por vía portal de la Biblioteca Virtual de la Salud (BVS) como Literatura Latinoamericana en Ciencias de la Salud, Scientific Eletronic Library Online y Base de Datos de la Enfermería, en artículos disponibles en su totalidad, en idioma portugués-BR, publicada desde 2013 hasta 2017. el análisis de los datos reveló tres temas, presentó los resultados: "el potencial evidenciado por los usuarios del servicio frontal Sistema Único de salud en la red de atención primaria"; "Las fragilidades relacionadas a la atención de los usuarios a los servicios de salud en el ámbito de la atención primaria" y la "importancia de la atención primaria como puerta de entrada de los usuarios en la red de los servicios de salud". Se toman como resultado, según la percepción de usuarios, que la atención primaria es considerada incipiente y un gran desafío para gestores. Se concluye que es importante emprender una discusión más sólida sobre las diferentes formas de acceso a los usuarios de la atención primaria a la salud y también vislumbrar acciones de mejora tanto en la planificación y en las relaciones entre todos los integrantes del equipo de salud y de los usuarios que buscan atención en el sistema único de salud, para que el principio de la integralidad sea de hecho vislumbrado.
\end{abstract}

Palabras clave: Atención Primaria a la Salud, Comportamiento del consumidor, Sistema único de Salud. 


\section{INTRODUÇÃo}

A moderna concepção de Atenção Primária à Saúde (APS) surgiu no Reino Unido, em 1920, no Relatório Dawson que preconizou a organização do sistema de atenção à saúde em diversos níveis: os serviços domiciliares, os centros de saúde primários, os centros de saúde secundários, os serviços suplementares e os hospitais de ensino (MENDES, 2015).

De acordo com Mendes (2015) esse clássico documento descreveu as funções de cada nível de atenção e as relações que deveriam existir entre eles e representa o texto fundante da regionalização dos sistemas de atenção à saúde organizada em bases populacionais, tendo influenciado a organização desses sistemas em vários países do mundo.

Demarzo (2011) destaca que o modelo de atenção baseado em centros de saúde comunitários remontava a iniciativas pioneiras francesas do final do século XIX, e americanas do início do século XX nas quais já se promoviam e efetivavam conceitos-chave, muitos incorporados pela APS no futuro tais como: população de risco; ações de base territorial; descentralização; assistência social; prevenção associada à assistência médica; educação sanitária; ações sobre o meio ambiente; e rede de atenção à saúde organizada em distritos.

A Portaria Ministerial $n^{\circ}$ 2.436, de 21 de Setembro de 2017, versa sobre a Política Nacional de Atenção Básica (PNAB) e apresenta orientações acerca da organização e do funcionamento das instituições de saúde, estabelece as diretrizes para a organização do componente atenção básica.

Reforça ainda que a Atenção Básica será a principal porta de entrada e centro de comunicação da rede de atenção à saúde e que tem como prioridade as equipes de estratégia saúde da família para sua expansão e consolidação. (BRASIL, 2017)

Faz-se necessária uma breve elucidação dos termos "Atenção Básica" e "Atenção Primária à Saúde" objeto de estudo da presente pesquisa. Sobre isto, Mello, Fontanella, Demarzo (2009) discorrem que há uma frequente discussão sobre a terminologia ideal para nomear o primeiro nível de atenção à saúde. No Brasil, a expressão "Atenção Básica" foi oficializada pelo Governo Federal, embora, em documentos oficiais brasileiros, identifiquese uma crescente utilização de "Atenção Primária à Saúde”.

Tais termos podem ser utilizados como sinônimos, sem que isto se torne um problema conceitual, visto que essa oscilação terminológica sugere uma disputa ideológica, 
em contraste com a tendência internacional do uso "atenção primária". Contudo, ao comparar diretamente as origens e significados dos diversos termos relacionados ao primeiro nível de atenção em saúde, há um confronto de ideias, principalmente no que tange a construção histórica, relações nem sempre refletidas. (MELLO, FONTANELLA, DEMARZO, 2009)

As diferentes interpretações, sua complexidade conceitual e a evolução de sua implementação levaram à utilização de diferentes termos para nomear a "atenção primária". Tal polissemia é vista tanto na literatura internacional quanto na nacional. Da atenção primária proposta em Alma-Ata até hoje, surgiram derivações, tem-se: atenção primária à saúde, atenção primária seletiva, atenção primária orientada para a comunidade e, mais recentemente, a atenção primária renovada (BRASIL, 2011).

De acordo com Brasil (2011) atualmente, alguns autores, o próprio Conselho Nacional de Secretários de Saúde - CONASS, e alguns documentos do Ministério da Saúde já vêm utilizando a terminologia internacionalmente reconhecida de APS. Assim, no Brasil, o Ministério da Saúde adotou a nomenclatura de atenção básica para definir APS, tendo como sua estratégia principal a Saúde da Família.

A respeito desse programa, foi instituído pelo Ministério da Saúde, em 1994, com o objetivo de reorganizar a prática assistencial em uma área territorial, com a atenção centrada na família, entendida e percebida em seu ambiente físico e social, com o intuito de possibilitar uma compreensão ampliada do processo saúde-doença e da intervenção que não se restrinja a práticas curativas (BRASIL, 2001).

Mas qual seria a definição de APS? Considerar-se-á neste artigo a definição internacionalmente reconhecida da Organização Mundial de Saúde (OMS) que trata a APS como sendo atenção essencial à saúde baseada em tecnologia e métodos práticos, cientificamente comprovados e socialmente aceitáveis, tornados universalmente acessíveis a indivíduos e famílias na comunidade por meios aceitáveis para eles e a um custo que tanto a comunidade como o país possa arcar em cada estágio de seu desenvolvimento, um espírito de autoconfiança e autodeterminação (OMS, 1978).

A OMS também considera a APS como parte integral do sistema de saúde do país, sendo o enfoque principal do desenvolvimento social e econômico global da comunidade. É o primeiro nível de contato dos indivíduos, da família e da comunidade com o sistema 
nacional de saúde, levando a atenção à saúde o mais próximo possível do local onde as pessoas vivem e trabalham, constituindo o primeiro elemento de um processo de atenção continuada à Saúde (OMS, 1978).

Starfield (2002) afirma que a atenção primária possibilita o acesso dos usuários aos serviços de saúde, considerando as necessidades e problemas mais comuns da comunidade, com o intuito de oferecer serviços de prevenção, cura e reabilitação para maximizar a saúde e o bem-estar.

De acordo com Arantes, Shimizu e Hamann (2016) não há dúvidas dos resultados favoráveis à saúde da população com a adoção da APS como elemento principal para organização dos serviços de saúde no Brasil, contudo, devido a heterogeneidade de contextos as suas potencialidades podem ser minimizadas ocasionado questionamentos quanto a sua credibilidade como organizador dos serviços de saúde.

Por questões permeadas por interesses políticos, econômicos e sociais, cenários complexos, diversificados, essa heterogeneidade pode ser vista como um dificultador para as ações e serviços de saúde. É notório que o modelo de APS no Brasil possui inúmeras potencialidades, tais como, promoção do acesso às populações historicamente excluídas e desassistidas, implantação em áreas rurais e ribeirinhas, diminuição dos indicadores de mortalidade, etc. (SHIMIZU E HAMANN, 2016)

Vários artigos científicos evidenciam a existência de desafios e fragilidades a serem superados no contexto da APS no Brasil, dentre eles pode-se citar as dificuldades de acesso ao sistema, considerado porta de entrada para os atendimentos à população. Estudos de Bonello e Corrêa (2014) apontam como principais dificuldades: ofertas insuficientes de serviços de saúde, características demográficas (locomoção para chegar até a unidade mais próxima), situação socioeconômica (renda familiar), costumes individuais, morbidades, atendimento anterior recebido, fatores ligado ao território. É sob este tipo de orientação que este estudo pretende se ancorar.

Baseado no exposto, a pesquisa em questão possui relevância científica, pois há carência de estudos que abordem o contexto da APS além de proporcionar à ampliação de novos vieses relacionados ao acesso dos usuários na atenção primária à saúde e as suas possíveis fragilidades. Salienta-se a importância social da pesquisa, pois, pode-se identificar as perspectivas dos usuários dos serviços de saúde sobre o atendimento prestado nas unidades básicas de saúde. 
Eventualmente, pode-se contribuir com informações genéricas que possam sensibilizar os gestores a refletir sobre a atual situação dos atendimentos nas unidades básicas de saúde (UBS), para o planejamento estratégico ideal, uma vez que poderão ser detectadas dificuldades e/ou fragilidades e estas servirão de subsídios para reflexões críticas, construtivas e gerar recomendações para os gestores de saúde dos municípios de todo o Brasil.

Portanto, o estudo tem como problema de pesquisa a seguinte indagação: quais os principais fatores que levam os usuários do SUS, a procurar os serviços de atenção primária à saúde? Existe alguma dificuldade de acesso aos serviços neste âmbito? Traz como hipótese a existência de fragilidades na organização dos serviços de saúde para a população, por conta do elevado crescimento populacional acelerado e da dificuldade de ampliação da rede de atendimentos em saúde, em especial a criação de novas Unidades Básicas de Saúde.

Dessa forma, o artigo tem como objetivo primário identificar através da literatura científica, as potencialidades e fragilidades diante do atendimento do usuário do SUS nas unidades básicas de saúde. E como objetivos secundários: descrever os principais fatores que dificultam o atendimento a saúde e salientar a importância da atenção básica como porta de entrada aos sistemas de saúde a fim de promover a integralidade e longitudinalidade amplamente discutida no âmbito da saúde.

\section{METODOLOGIA}

Trata-se de uma pesquisa bibliográfica, pois foi realizada com o intuito de levantar um conhecimento disponível sobre teorias, a fim de analisar, produzir ou explicar um objeto sendo investigado (KAIMEN ET AL, 2008).

Foram realizadas buscas nos bancos e bases de dados na área da saúde, sendo acessadas por via portal da Biblioteca Virtual da Saúde (BVS), tais como LILACS (Literatura Latino-Americana em Ciências da Saúde), Scielo (Scientific Eletronic Library Online) e BDENF (Base de Dados da Enfermagem), utilizou-se os descritores: "Atenção Primária à Saúde. "Comportamento do Consumidor" e "Sistema Único de Saúde."

Procedeu-se a inclusão dos artigos disponíveis em bancos de dados na internet, disponíveis na íntegra, em idioma Português-BR, publicados no período de 2013 a 2017. 
Foram consideradas teses, dissertações, monografias, publicações do Ministério da Saúde e Organizações Internacionais, além de resumos na íntegra relacionados ao objeto de estudo. Como critério de exclusão, foram excluídos artigos em língua diferente do Português-BR e materiais cujos descritores, não caracterizassem o objeto de estudo, além de publicações anteriores a 2013.

Utilizando-se os descritores mencionados, procedeu-se à busca emergindo 50 publicações. A partir disso, iniciou-se a utilização dos critérios de inclusão como filtros dos artigos. Estes foram submetidos a uma pré- análise de acordo com a temática do estudo, totalizando 32 artigos lidos na íntegra, destes, 23 obedeceram os critérios de inclusão e 09 artigos foram descartados por não atenderem os objetivos do estudo, conforme evidenciado na figura abaixo.

A figura 1 mostra o processo de seleção dos artigos em suas diferentes etapas e o respectivo número de artigos recuperados em cada uma. As referências captadas foram incluídas em uma biblioteca única no programa EndNote.

Após a seleção, foram criadas três bibliotecas no programa EndNote, que deram origem às categorias temáticas. A primeira, relacionada às potencialidades evidenciadas pelos usuários do SUS diante do atendimento na rede básica de saúde, a segunda relacionada às fragilidades relacionadas ao acesso dos usuários aos serviços de saúde no âmbito da atenção primária à saúde e a terceira relacionada à importância da atenção primária enquanto porta de entrada dos usuários na rede dos serviços de saúde, nas quais constavam todas as referências selecionadas e os respectivos artigos completos em Portable Document Format - PDF - (Formato Portátil de Documento).

As obras selecionadas foram descritas em um quadro sinóptico, contendo as seguintes informações: ano da publicação, título, autores, periódico, objetivos, tipo de pesquisa, resultados e conclusões.

De acordo com a Resolução 466/12 não foi necessário a aprovação do Comitê de Ética em Pesquisa, devido a não utilização e manuseio de dados sigilosos e de participação de seres humanos. No entanto, o projeto foi encaminhado ao Comitê de Ética e Pesquisa da Faculdade Estácio de Macapá, e obteve o certificado de isenção com êxito. 
Figura 1 - Fluxograma do processo de seleção dos artigos pesquisados. O número de artigos em cada etapa está indicado entre parênteses.

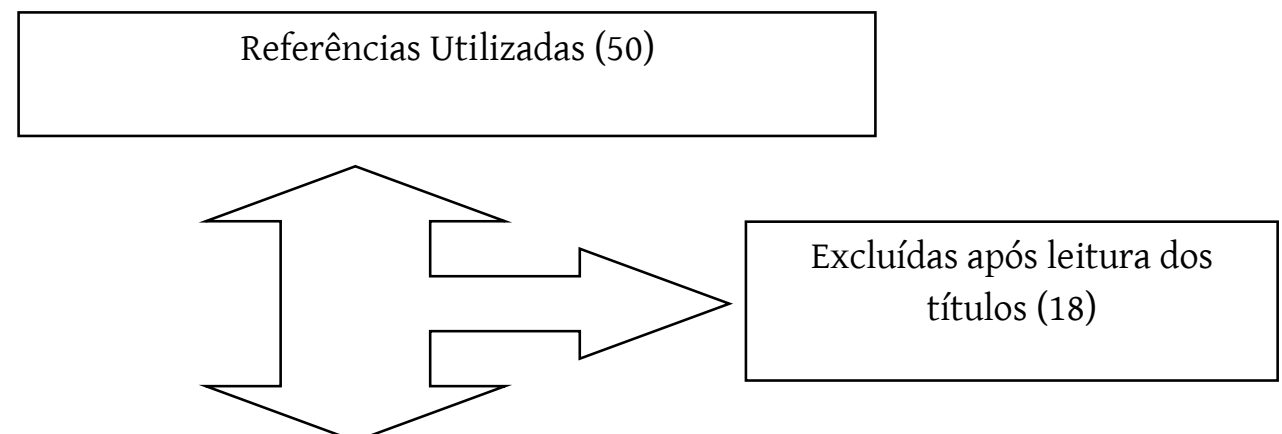

Selecionadas para a leitura dos resumos (32)

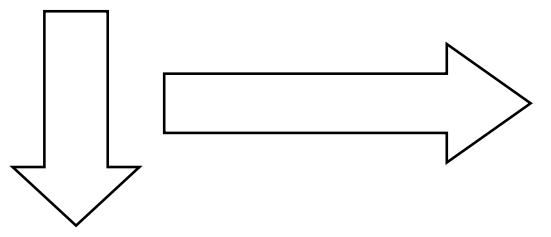

Excluídas após leitura na integra (9)

Artigos selecionados para leitura na íntegra (23)

Potencialidades do SUS evidenciadas pelos usuários

(7)

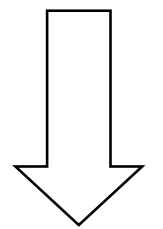

Fragilidades do SUS evidenciadas pelos usuários

(10)

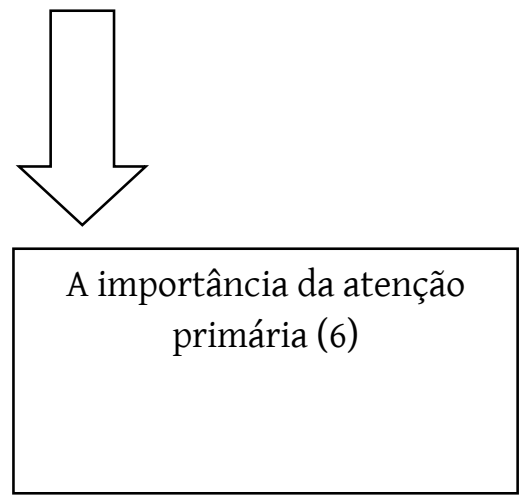

Fonte: Própria.

\section{RESULTADOS E DISCUSSÃO}

A leitura minuciosa dos artigos científicos selecionados emergiu em três categorias temáticas, demonstrados com auxílio de tabelas definidas a seguir: 


\section{Categoria 1: As potencialidades evidenciadas pelos usuários do SUS diante do}

\section{atendimento na rede básica de saúde.}

Esta categoria foi abordada por 7 (sete) estudos, correspondendo à 30,4\% do total, sendo estes destacados no quadro 1.

Quadro 1 - Caracterização dos estudos sobre "As potencialidades evidenciadas pelos usuários do SUS diante do atendimento na rede básica de saúde"

\begin{tabular}{|c|c|c|c|c|}
\hline $\begin{array}{c}\text { ARTIGO/ } \\
\text { AUTORES/AN } \\
0\end{array}$ & $\begin{array}{l}\text { PERIÓDI } \\
\text { CO }\end{array}$ & $\begin{array}{c}\text { TIPO DE } \\
\text { PESQUISA }\end{array}$ & OBJETIVO & RESULTADO \\
\hline $\begin{array}{l}\text { Estratégias } \\
\text { para } \\
\text { consolidação } \\
\text { da } \\
\text { coordenação } \\
\text { do cuidado } \\
\text { pela atenção } \\
\text { básica } \\
\text { ALMEIDA, } \\
\text { MARIN,CASOT } \\
\text { TI (2017) }\end{array}$ & $\begin{array}{l}\text { Scientifi } \\
\text { c } \\
\text { Electroni } \\
\text { c Library } \\
\text { (SCIELO) }\end{array}$ & $\begin{array}{lr}\text { Estudo descritivo } \\
\text { com } & 1.313 \\
\text { usuários e } & 324 \\
\text { equipes rérica no } \\
\text { atenção básica no } \\
\text { município do Rio } \\
\text { de Janeiro. }\end{array}$ & $\begin{array}{l}\text { Avaliar a organização } \\
\text { da porta de entrada, } \\
\text { resolutividade e } \\
\text { continuidade do } \\
\text { cuidado, integração } \\
\text { horizontal, } \\
\text { organização dos } \\
\text { fluxos e acesso à rede } \\
\text { de referência, } \\
\text { continuidade } \\
\text { informacional e } \\
\text { comunicação entre } \\
\text { profissionais. }\end{array}$ & $\begin{array}{l}\text { Os resultados indicaram que a } \\
\text { atenção primária em saúde se } \\
\text { consolidou como porta de entrada } \\
\text { preferencial. }\end{array}$ \\
\hline $\begin{array}{l}\text { Contribuições e } \\
\text { desafios da } \\
\text { estratégia } \\
\text { saúde da } \\
\text { Família na } \\
\text { Atenção } \\
\text { Primária à } \\
\text { saúde no } \\
\text { Brasil. } \\
\text { ARANTES, } \\
\text { SHIMIZU, } \\
\text { HAMANN } \\
\text { (2016) }\end{array}$ & $\begin{array}{l}\text { Ciência e } \\
\text { Saúde } \\
\text { Coletiva }\end{array}$ & $\begin{array}{l}\text { Revisão de } \\
\text { literatura, no site } \\
\text { da Bireme do } \\
\text { período de } 2002 \text { a } \\
\text { 2011, abrangendo } \\
\text { base de dados } \\
\text { como Lilacs, } \\
\text { IBECS, Medline, } \\
\text { Biblioteca } \\
\text { Cochrane } \\
\text { SciELO. }\end{array}$ & $\begin{array}{l}\text { Identificar e analisar } \\
\text { as principais } \\
\text { contribuições e os } \\
\text { desafios da ESF para o } \\
\text { desenvolvimento da } \\
\text { APS brasileira, com a } \\
\text { finalidade de refletir } \\
\text { sobre os aspectos que } \\
\text { podem afetar a } \\
\text { sustentabilidade } \\
\text { desse modelo. }\end{array}$ & $\begin{array}{l}\text { APS é vista como eixo principal do } \\
\text { sistema de saúde. Desta feita, a sua } \\
\text { sustentabilidade e o seu } \\
\text { desenvolvimento dependem do } \\
\text { grau de investimento do Estado } \\
\text { para que sejam feitas os } \\
\text { investimentos necessário na } \\
\text { atenção primaria. }\end{array}$ \\
\hline $\begin{array}{l}\text { Atributos } \\
\text { essenciais da } \\
\text { atenção } \\
\text { Primária e a } \\
\text { estratégia } \\
\text { Saúde da } \\
\text { família } \\
\text { OLIVEIRA E } \\
\text { PEREIRA (2013) }\end{array}$ & $\begin{array}{l}\text { Revista } \\
\text { Brasileir } \\
\text { a de } \\
\text { Enferma } \\
\text { gem }\end{array}$ & Artigo de Revisão & $\begin{array}{l}\text { Este estudo propõe-se } \\
\text { a realizar uma } \\
\text { reflexão teórica sobre } \\
\text { a presença dos } \\
\text { atributos essenciais } \\
\text { da APS na ESF. }\end{array}$ & $\begin{array}{l}\text { A efetividade da política de saúde } \\
\text { será garantida com a reafirmação } \\
\text { contundente de um sistema } \\
\text { público de saúde socialmente } \\
\text { superior ao modelo liberal ou } \\
\text { médico tradicional, que somente a } \\
\text { luta constante dos movimentos } \\
\text { sociais pelo direito à saúde pode } \\
\text { garantir. }\end{array}$ \\
\hline $\begin{array}{l}\text { Núcleo de } \\
\text { Apoio à Saúde } \\
\text { da Família: } \\
\text { potencialidade } \\
\text { s como } \\
\text { dispositivo de } \\
\text { mudança na } \\
\text { Atenção Básica } \\
\text { em saúde }\end{array}$ & $\begin{array}{l}\text { Saúde } \\
\text { Debate }\end{array}$ & $\begin{array}{l}\text { Abordagem } \\
\text { qualitativa, de } \\
\text { caráter } \\
\text { compreensivo, } \\
\text { com os gestores da } \\
\text { Diretoria de } \\
\text { Atenção Primária } \\
\text { à Saúde de } \\
\text { município de }\end{array}$ & $\begin{array}{l}\text { O Nasf } r \text { tem } \\
\text { potencialidade para } \\
\text { se constituir } \\
\text { enquanto dispositivo } \\
\text { de mudança nas } \\
\text { práticas de cuidado e } \\
\text { de gestão? Diante do } \\
\text { exposto, o presente } \\
\text { trabalho }\end{array}$ & $\begin{array}{l}\text { Os resultados revelaram } \\
\text { predominância do objetivo } \\
\text { estratégico do Nasf enquanto } \\
\text { dispositivo, que a gestão colegiada } \\
\text { se mostrou um arranjo potente } \\
\text { para a gestão e, por fim, que a } \\
\text { implantação do Nasf pode ser } \\
\text { compreendida como uma ação que } \\
\text { potencializa a produção de }\end{array}$ \\
\hline
\end{tabular}


Sistema Único de Saúde: uma revisão bibliográfica

\begin{tabular}{|c|c|c|c|c|}
\hline $\begin{array}{c}\text { VOLPONI, } \\
\text { GARANHANI } \\
\text { CARVALHO } \\
(2015)\end{array}$ & & \begin{tabular}{|lr} 
grande porte & do \\
Paraná, & no \\
período & de \\
setembro/2012 & a \\
abril/2013, & por \\
meio & de \\
observação & e \\
entrevistas. &
\end{tabular} & $\begin{array}{l}\text { analisar } \\
\text { possibilidade, a partir } \\
\text { das ações } \\
\text { desenvolvidas por } \\
\text { uma equipe gestora } \\
\text { da AB, de um } \\
\text { município de grande } \\
\text { porte. }\end{array}$ & mudanças na Atenção Básica. \\
\hline $\begin{array}{c}\text { Práticas de } \\
\text { cuidado da } \\
\text { enfermeira na } \\
\text { Estratégia } \\
\text { Saúde da } \\
\text { Família } \\
\text { SANTOS ET AL } \\
\text { (2016) }\end{array}$ & $\begin{array}{l}\text { Revista } \\
\text { Brasileir } \\
\text { a de } \\
\text { Enferma } \\
\text { gem } \\
\text { REBEn }\end{array}$ & $\begin{array}{l}\text { Pesquisa } \\
\text { qualitativa } \\
\text { realizada com } 34 \\
\text { usuários } \\
\text { cadastrados em } \\
\text { sete Unidades de } \\
\text { Saúde da Família } \\
\text { de um município } \\
\text { baiano entre } \\
\text { junho e dezembro } \\
\text { de 2014. Os } \\
\text { resultados foram } \\
\text { organizados pela } \\
\text { técnica de análise } \\
\text { de conteúdo. }\end{array}$ & $\begin{array}{l}\text { Analisar as práticas } \\
\text { de cuidado de } \\
\text { enfermeiras que } \\
\text { atuam nas equipes da } \\
\text { Estratégia Saúde da } \\
\text { Família, sob a ótica de } \\
\text { usuários. }\end{array}$ & $\begin{array}{l}\text { Os usuários mostraram satisfação } \\
\text { com o atendimento da enfermeira } \\
\text { em virtude da escuta, acolhimento } \\
\text { e resolubilidade de suas } \\
\text { necessidades de saúde, apesar da } \\
\text { ênfase em procedimentos e } \\
\text { programas direcionados aos } \\
\text { grupos populacionais. } \\
\text { insatisfação decorre da postura } \\
\text { autoritária, prescritiva e inflexível } \\
\text { no cuidado produzido pela } \\
\text { enfermeira. Destacaram ainda que } \\
\text { as visitas domiciliares são } \\
\text { direcionadas aos acamados e de } \\
\text { forma mais restrita às ações } \\
\text { preventivas. As ações educativas } \\
\text { ocorrem durante a consulta de } \\
\text { enfermagem e na UBS. }\end{array}$ \\
\hline $\begin{array}{l}\text { Avaliação de } \\
\text { serviços de } \\
\text { saúde bucal: } \\
\text { um estudo } \\
\text { comparativo } \\
\text { Brunhauser, } \\
\text { Magro, Neves } \\
\text { (2013) }\end{array}$ & $\begin{array}{c}\text { RFO } \\
\text { PASSO } \\
\text { FUNDO }\end{array}$ & \begin{tabular}{|lr}
\multicolumn{2}{|l}{ Transversal de } \\
base populacional, \\
\multicolumn{2}{|l}{ amostragem por } \\
conglomerado. \\
Utilizou-se r o \\
(QASSaB) \\
Questionário & de \\
Avaliação r da \\
Qualidade r dos \\
Serviços de & Saúde \\
Bucal, & \\
devidamente & \\
validado.
\end{tabular} & $\begin{array}{l}\text { Avaliar o acesso e a } \\
\text { satisfação dos } \\
\text { usuários dos serviços } \\
\text { odontológicos do } \\
\text { SUS, comparando } \\
\text { usuários da ESF com } \\
\text { usuários de UBSs } \\
\text { convencionais, em } \\
\text { Não-Me-Toque/RS, } \\
\text { Brasil. }\end{array}$ & 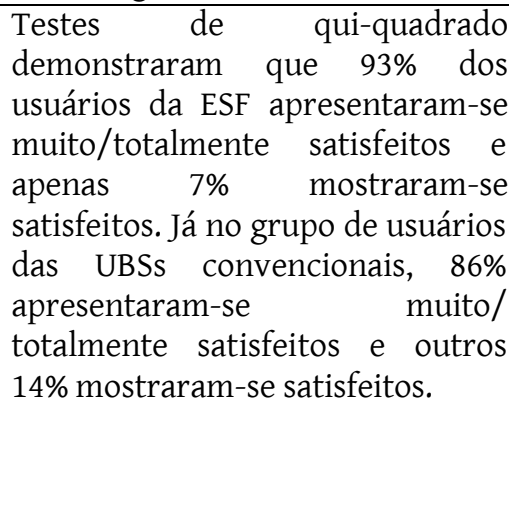 \\
\hline $\begin{array}{l}\text { Satisfação do } \\
\text { usuário da } \\
\text { Atenção Básica } \\
\text { em Saúde por } \\
\text { regiões do } \\
\text { Brasil: } 1^{\circ} \text { ciclo } \\
\text { de avaliação } \\
\text { externa do } \\
\text { PMAQ-AB } \\
\text { PROTASIO ET } \\
\text { AL (2017) }\end{array}$ & $\begin{array}{l}\text { Ciência e } \\
\text { Saúde } \\
\text { Coletiva }\end{array}$ & $\begin{array}{l}\text { Utilizando dados } \\
\text { secundários do } 1^{\circ} \\
\text { Ciclo do PMAQAB, } \\
\text { desenvolveu-se } \\
\text { modelos de } \\
\text { regressão logística } \\
\text { por região tendo } \\
\text { como variável } \\
\text { dependente a } \\
\text { satisfação do } \\
\text { usuário (obtida } \\
\text { por análise de } \\
\text { agrupamento). }\end{array}$ & $\begin{array}{l}\text { Este estudo objetiva } \\
\text { identificar os } \\
\text { principais fatores que } \\
\text { influenciam na } \\
\text { Satisfação do Usuário } \\
\text { com os serviços de } \\
\text { Atenção Básica por } \\
\text { regiões do Brasil. }\end{array}$ & $\begin{array}{l}\text { Resolver seus problemas na US e } \\
\text { sentir-se respeitado pelos } \\
\text { profissionais de saúde são os } \\
\text { fatores mais importantes, em } \\
\text { todas as regiões do Brasil, } \\
\text { referente à sua satisfação. Porém, } \\
\text { podem-se destacar outros fatores } \\
\text { por região: o horário de } \\
\text { funcionamento (Nordeste); } \\
\text { profissionais perguntarem pelos } \\
\text { familiares (Norte); interesse dos } \\
\text { profissionais sobre outras } \\
\text { necessidades de saúde (Centro- } \\
\text { Oeste); ser escutado sem ter hora } \\
\text { marcada (Sul); e retirar suas } \\
\text { dúvidas após a consulta (Sudeste). } \\
\text { Conclui-se que os fatores } \\
\text { influenciadores da satisfação dos }\end{array}$ \\
\hline
\end{tabular}




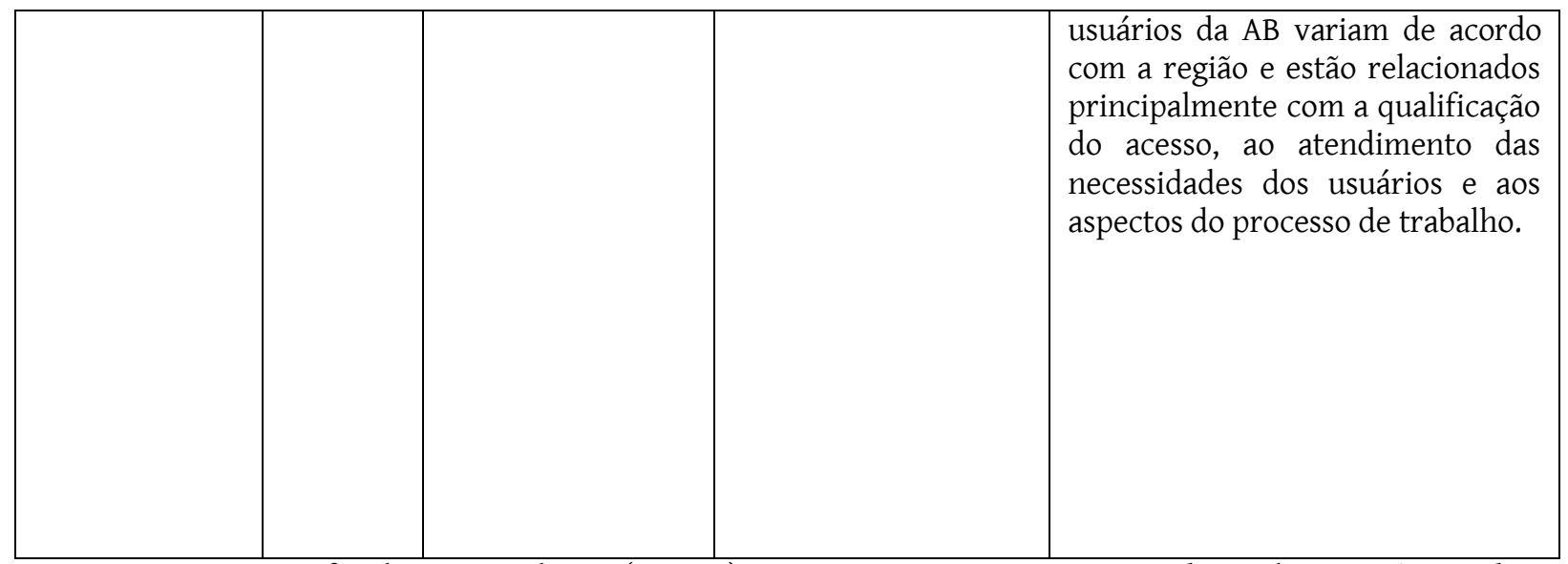

Fonte: Scientific Electronic Library (SCIELO), Literatura Latino-Americana e do Caribe em Ciências da Saúde (LILACS) e Medical Literature Analysis and Retrieval System on-line (MEDLINE) - anos de 2013 a 2017.

Sobre "as potencialidades evidenciadas pelos usuários do SUS diante do atendimento na rede básica de saúde" Almeida, Marin, Casotti (2017) em sua pesquisa ratificaram que a atenção primária em saúde se consolida como porta de entrada preferencial. Arantes, Shimizu, Hamann (2016) também compartilham dessa afirmativa ao discorrer que a APS é vista como eixo principal do sistema de saúde, no entanto destacam que a sua sustentabilidade e o seu desenvolvimento dependem do grau de investimento do Estado para que sejam feitas os investimentos necessários na atenção primaria.

De acordo com Oliveira e Pereira (2013) a efetividade da política de saúde será garantida com a reafirmação contundente de um sistema público de saúde socialmente superior ao modelo liberal ou médico tradicional, que somente a luta constante dos movimentos sociais pelo direito à saúde pode garantir.

Sobre a satisfação dos usuários Brunhauser, Magro, Neves (2013) demonstraram que 93\% dos usuários da ESF apresentaram-se muito/totalmente satisfeitos e apenas 7\% mostraram-se satisfeitos. Já no grupo de usuários das UBS's convencionais, 86\% apresentaram-se muito/ totalmente satisfeitos e outros $14 \%$ mostraram-se satisfeitos. Tal achado confirma a ESF como principal estratégia de gestão da APS.

Os resultados de Volponi, Garanhani, Carvalho (2015) revelaram predominância do objetivo estratégico do Núcleo de Apoio a Saúde da Família (NASF) enquanto dispositivo, no qual a gestão colegiada se mostrou um arranjo potente para a gestão e que a implantação do NASF pode ser compreendida como uma ação que potencializa a produção de mudanças na Atenção Básica. 
O NASF constitui-se de uma equipe multiprofissional e interdisciplinar composta por categorias de profissionais da saúde, complementar às equipes que atuam na Atenção Básica, que atuam de maneira integrada para dar suporte (clínico, sanitário e pedagógico) aos profissionais das equipes de Saúde da Família (eSF) e de Atenção Básica (eAB). (BRASIL, 2017)

O NASF pode potencializar as mudanças nos territórios pois recebe a demanda por negociação e realiza discussão compartilhada com as equipes que apoia, as ajuda a evitar ou qualificar os encaminhamentos realizados para outros pontos de atenção. (VOLPONI, GARANHANI, CARVALHO, 2015)

Protasio et al (2017) identificaram que "resolver seus problemas na US e sentir-se respeitado pelos profissionais de saúde" são os fatores mais importantes, em todas as regiões do Brasil, referente à sua satisfação. Porém, podem-se destacar outros fatores por região: o horário de funcionamento (Nordeste); profissionais perguntarem pelos familiares (Norte); interesse dos profissionais sobre outras necessidades de saúde (Centro-Oeste); ser escutado sem ter hora marcada (Sul); e retirar suas dúvidas após a consulta (Sudeste). Tais autores concluíram que os fatores influenciadores da satisfação dos usuários da $A B$ variam de acordo com a região e estão relacionados principalmente com a qualidade do acesso, ao atendimento das necessidades dos usuários e aos aspectos do processo de trabalho.

Ainda sobre a satisfação dos usuários no quesito atendimento do profissional Enfermeiro na atenção primária Santos et al (2016)evidenciaram que os usuários mostraram satisfação com o atendimento da enfermeira em virtude da escuta, acolhimento e resolubilidade de suas necessidades de saúde, apesar da ênfase em procedimentos e programas direcionados aos grupos populacionais. A insatisfação decorre da postura autoritária, prescritiva e inflexível no cuidado produzido pela enfermeira. Destacaram ainda que as visitas domiciliares são direcionadas aos acamados e de forma mais restrita às ações preventivas. As ações educativas ocorrem durante a consulta de enfermagem e na UBS.

Considerando os princípios e diretrizes do SUS e as estratégias de operacionalização é indiscutível que a APS representa a principal porta de entrada para o sistema de serviços de saúde no contexto brasileiro.

Reconhecer as necessidades e problemas da população é um dos primeiros passos para evidenciar a perspectiva da integralidade, o atendimento contínuo e longitudinal aos 
usuários do SUS. Dar voz aos usuários também permite identificar fragilidades e características que por vezes passam despercebidas pelas equipes assim como pelos gestores em saúde.

\section{Categoria 2: As fragilidades relacionadas ao acesso dos usuários aos serviços de saúde no âmbito da atenção primária à saúde.}

Esta categoria foi abordada por 10 (dez) estudos, correspondendo à 43,4 \% do total, sendo estes destacados no quadro 2.

Quadro 2 - caracterização dos estudos sobre "As fragilidades relacionadas ao acesso dos usuários aos serviços de saúde no âmbito da APS".

\begin{tabular}{|c|c|c|c|c|}
\hline $\begin{array}{c}\text { ARTIGO/ } \\
\text { AUTORES/ANO }\end{array}$ & PERIÓDICO & $\begin{array}{c}\text { TIPO DE } \\
\text { PESQUISA }\end{array}$ & OBJETIVO & RESULTADO \\
\hline $\begin{array}{l}\text { Avaliação da atenção } \\
\text { primária: o ponto de } \\
\text { vista de usuários. } \\
\text { GONTIJO et al } \\
\text { (2017) }\end{array}$ & Saúde Debate & $\begin{array}{l}\text { Trata-se de estudo } \\
\text { transversal com } \\
\text { usuários adultos } \\
\text { vinculados a } \\
\text { equipes de APS. }\end{array}$ & $\begin{array}{lr}\text { Avaliar } & \text { atributos } \\
\text { da } & \text { Atenção } \\
\text { Primária } & \text { à Saúde } \\
\text { (APS), sob r a } & \text { sobcero } \\
\text { percepçáo } & \text { de } \\
\text { usuários. } & \end{array}$ & $\begin{array}{l}\text { Conclui-se que os atributos da } \\
\text { APS analisados receberam } \\
\text { avaliação heterogênea e a } \\
\text { maioria necessita de um olhar } \\
\text { mais atento e investimento } \\
\text { por parte dos gestores e } \\
\text { profissionais. }\end{array}$ \\
\hline $\begin{array}{l}\text { Avaliação da } \\
\text { qualidade do } \\
\text { acesso na atenção } \\
\text { primária de uma } \\
\text { grande cidade } \\
\text { brasileira na } \\
\text { perspectiva dos } \\
\text { usuários. } \\
\text { CAMPOS ET AL } \\
\text { (2014) }\end{array}$ & Saúde Debate & 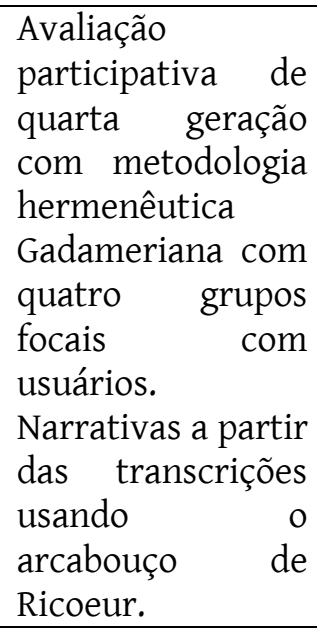 & $\begin{array}{l}\text { Compreender } \\
\text { como usuários do } \\
\text { sistema de saúde } \\
\text { de uma metrópole } \\
\text { brasileira avaliam o } \\
\text { acesso aos serviços } \\
\text { de atenção } \\
\text { primária. }\end{array}$ & $\begin{array}{l}\text { A atenção primária é } \\
\text { reconhecida como a porta de } \\
\text { entrada do sistema de saúde, } \\
\text { mas o acesso é dificultado por: } \\
\text { problemas de organização; uso } \\
\text { do acolhimento como barreira } \\
\text { ao acesso; falta de recursos } \\
\text { humanos; dificuldades em dar } \\
\text { seguimento ao tratamento. O } \\
\text { modelo centrado na doença e } \\
\text { a falta de análise crítica } \\
\text { podem induzir a descrença } \\
\text { nos resultados da atenção } \\
\text { primária. }\end{array}$ \\
\hline $\begin{array}{l}\text { Quando a porta de } \\
\text { entrada não } \\
\text { resolve: análise das } \\
\text { unidades de saúde } \\
\text { da família no } \\
\text { município de Rio } \\
\text { Branco, Acre. } \\
\text { CHAGAS } \\
\text { VASCONCELLOS } \\
\text { (2013) }\end{array}$ & $\begin{array}{c}\text { Scientific } \\
\text { Electronic } \\
\text { Library } \\
\text { (SCIELO) }\end{array}$ & 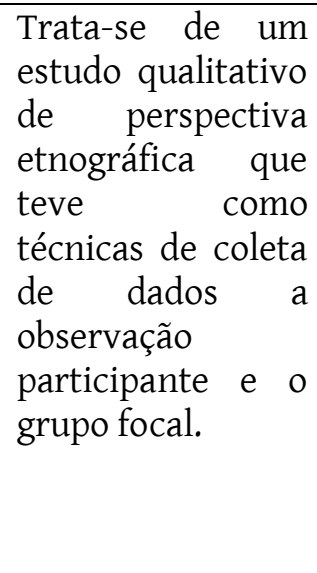 & $\begin{array}{l}\text { Conhecer e } \\
\text { compreender a } \\
\text { realidade de } \\
\text { algumas Unidades } \\
\text { de Saúde da Família } \\
\text { do município de } \\
\text { Rio Branco-Acre, } \\
\text { no sentido de } \\
\text { contribuir para a } \\
\text { reflexão sobre uma } \\
\text { das estruturas tão } \\
\text { complexa, como as } \\
\text { demais, que é "a }\end{array}$ & $\begin{array}{l}\text { Os resultados mostram que o } \\
\text { trabalho das equipes de saúde } \\
\text { da família no Município de Rio } \\
\text { Branco é centrado no médico } \\
\text { e no atendimento curativo e } \\
\text { que alguns profissionais } \\
\text { organizam seu processo de } \\
\text { trabalho de forma individual e } \\
\text { fragmentada, dificultando o } \\
\text { trabalho em equipe. }\end{array}$ \\
\hline
\end{tabular}




\begin{tabular}{|c|c|c|c|c|}
\hline & & & \begin{tabular}{|l|} 
porta de entrada" \\
na atenção básica, \\
do sistema de \\
saúde brasileiro. \\
\end{tabular} & \\
\hline $\begin{array}{l}\text { Acolhimento na } \\
\text { Atenção Primária à } \\
\text { Saúde: revisão } \\
\text { integrativa. } \\
\text { COUTINHO, } \\
\text { BARBIERI, SANTOS } \\
(2015)\end{array}$ & $\begin{array}{l}\text { Saúde } \\
\text { Debate }\end{array}$ & \begin{tabular}{|rr} 
Trata-se de & uma \\
revisão & \\
integrativa, & \\
relacionada & \\
também & ao \\
acolhimento & no \\
âmbito & da \\
Estratégia & Saúde \\
da Família. &
\end{tabular} & $\begin{array}{l}\text { Analisar o } \\
\text { conhecimento } \\
\text { produzido sobre o } \\
\text { acolhimento na } \\
\text { Atenção Primária à } \\
\text { Saúde, nos últimos } \\
\text { oito anos. }\end{array}$ & $\begin{array}{l}\text { O acolhimento ainda não está } \\
\text { totalmente sistematizado nos } \\
\text { modelos de atenção à saúde, } \\
\text { podendo ser esta uma } \\
\text { justificativa para as } \\
\text { dificuldades apresentadas } \\
\text { tanto por profissionais quanto } \\
\text { por usuários. São necessários } \\
\text { estudos com novas } \\
\text { abordagens ou estratégias } \\
\text { para verificar se estas têm } \\
\text { reais impacto na qualidade dos } \\
\text { serviços e na satisfação dos } \\
\text { usuários. }\end{array}$ \\
\hline $\begin{array}{l}\text { Percepções de } \\
\text { usuários atendidos } \\
\text { em um Pronto } \\
\text { Atendimento: olhar } \\
\text { sobre a Atenção } \\
\text { Primária à Saúde. } \\
\text { BARATIERI ET AL. } \\
\text { (2017) }\end{array}$ & $\begin{array}{l}\text { Revista de } \\
\text { Saúde Pública } \\
\text { do Paraná. }\end{array}$ & $\begin{array}{l}\text { Descritivo, } \\
\text { qualitativo, com } 24 \\
\text { usuários da UPA de } \\
\text { município do Sul } \\
\text { do país, coleta de } \\
\text { dados em } \\
\text { fev/março de 2015, } \\
\text { por entrevista } \\
\text { semiestruturada, e } \\
\text { analisados pela } \\
\text { análise de } \\
\text { conteúdo. }\end{array}$ & \begin{tabular}{|l|} 
compreender os \\
motivos que levam \\
os usuários a buscar \\
as Unidades de \\
Pronto \\
Atendimento (UPA) \\
quando o problema \\
de saúde poderia ser \\
resolvido no âmbito \\
da Atenção Primária \\
à Saúde (APS).
\end{tabular} & $\begin{array}{l}\text { Descompasso entre a visão } \\
\text { médico-centrada e a } \\
\text { inadequação das equipes de } \\
\text { saúde da APS para atenção à } \\
\text { demanda espontânea; } \\
\text { acolhimento deficitário na APS } \\
\text { gera dificuldades de acesso e } \\
\text { baixa resolutividade e } \\
\text { desarticulação entre UPA e } \\
\text { APS. Necessidade de } \\
\text { estruturação da coordenação } \\
\text { do cuidado. Conclui-se que as } \\
\text { UPAs são vistas pela população } \\
\text { como mais resolutivas, } \\
\text { havendo necessidade de } \\
\text { ordenar fluxos de atendimento } \\
\text { e educar/informar a população } \\
\text { sobre seu funcionamento. }\end{array}$ \\
\hline $\begin{array}{l}\text { Atenção Primária à } \\
\text { Saúde:coordenadora } \\
\text { do cuidado em } \\
\text { redes } \\
\text { regionalizadas? } \\
\text { Almeida e Santos } \\
\text { (2016) }\end{array}$ & $\begin{array}{c}\text { Revista de } \\
\text { Saúde Publica }\end{array}$ & $\begin{array}{lr}\text { Estudo de caso, } \\
\text { com abordagem } \\
\text { quantitativa } \\
\text { qualitativa. } \\
\text { Realizadas } \\
\text { entrevistas } \\
\text { semiestruturadas } \\
\text { com gestores } \\
\text { municipais, } \\
\text { regionais r e } \\
\text { estaduais e estudo } \\
\text { transversal com } \\
\text { aplicação r de } \\
\text { questionários para } \\
\text { médicos, r r } \\
\text { enfermeiros re } \\
\text { usuários da ESF em }\end{array}$ & $\begin{array}{l}\text { Analisar o alcance } \\
\text { da coordenação do } \\
\text { cuidado r pela } \\
\text { Atenção } \\
\text { Saúde em rimária à } \\
\text { regiões de saúde. }\end{array}$ & $\begin{array}{l}\text { A função de porta de entrada } \\
\text { preferencial pela APS } \\
\text { deparava-se com forte } \\
\text { concorrência de serviços } \\
\text { ambulatoriais hospitalares e de } \\
\text { pronto-atendimento, } \\
\text { desarticulados da rede. } \\
\text { Problemas de acesso e oferta de } \\
\text { atenção especializada eram } \\
\text { agravados pela dependência do } \\
\text { setor privado nas regiões, } \\
\text { ainda que tenham sido } \\
\text { observados avanços na } \\
\text { institucionalização de fluxos } \\
\text { desde a Atenção Primária à } \\
\text { Saúde. A contrarreferência era } \\
\text { deficiente e a comunicação }\end{array}$ \\
\hline
\end{tabular}




\begin{tabular}{|c|c|c|c|c|}
\hline & & $\begin{array}{l}\text { três municípios da } \\
\text { Bahia. }\end{array}$ & & interprofissional escassa. \\
\hline $\begin{array}{c}\text { Fortalezas e } \\
\text { fragilidades do } \\
\text { atendimento nas } \\
\text { UBS tradicionais e } \\
\text { da estratégia de } \\
\text { saúde da família } \\
\text { pela ótica dos } \\
\text { usuários. } \\
\text { MARIN, } \\
\text { MARCHIOLI, } \\
\text { MORACVICK } \\
\text { (2013) }\end{array}$ & $\begin{array}{c}\text { Texto } \\
\text { Contexto } \\
\text { Enfermagem } \\
\text { Florianópolis }\end{array}$ & $\begin{array}{lr}\text { Investigação } & \text { de } \\
\text { abordagem } & \\
\text { qualitativa, a partir } \\
\text { de entrevistas } & \text { com } \\
\text { usuários } & \text { que } \\
\text { utilizam } & \text { as } \\
\text { distintas } & \\
\text { modalidades } & \text { de } \\
\text { atenção à saúde. } & \end{array}$ & \begin{tabular}{|lrr} 
A & pesquisa & teve \\
como & objetivo \\
analisar & as \\
fortalezas & e & as \\
limitações & & da \\
Estratégia & Saúde & da \\
Família & e & da \\
Unidade & Básica & de \\
Saúde tradicional na \\
ótica dos \\
pautandarios, \\
dimensões & nas \\
avaliação & de \\
atenção primária à \\
saúde proposta & por \\
\multicolumn{2}{l}{ Starfield. } &
\end{tabular} & $\begin{array}{l}\text { As fragilidades e as fortalezas } \\
\text { das duas modalidades } \\
\text { assemelham-se quanto ao } \\
\text { acesso, porta de entrada, oferta } \\
\text { de serviços de saúde de } \\
\text { diferentes níveis de densidade } \\
\text { tecnológica e sua articulação. } \\
\text { Para os usuários da ESF, o } \\
\text { vínculo, a longitudinalidade e o } \\
\text { enfoque familiar ocorrem de } \\
\text { forma mais efetiva. Quanto à } \\
\text { equipe profissional, os usuários } \\
\text { da UBS tradicional } \\
\text { demonstram maior satisfação. } \\
\text { Para os usuários da ESF, ao se } \\
\text { disponibilizar apenas médico } \\
\text { generalista, não se atende a } \\
\text { todas as necessidades. Háa } \\
\text { necessidade de ajustes nas duas } \\
\text { modalidades. }\end{array}$ \\
\hline $\begin{array}{l}\text { Análise da eficiência } \\
\text { na atenção primária } \\
\text { à saúde sob a ótica } \\
\text { dos profissionais da } \\
\text { área } \\
\quad \text { CABRAL ET AL } \\
\quad(2016)\end{array}$ & $\begin{array}{l}\text { Revista de } \\
\text { Gestão em } \\
\text { Sistemas de } \\
\text { Saúde }\end{array}$ & 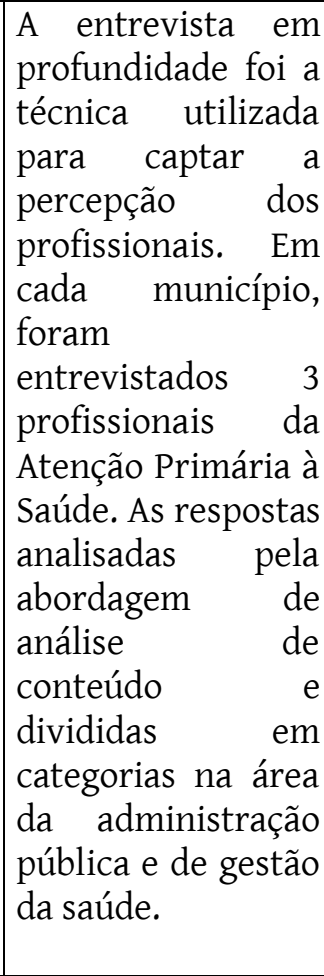 & $\begin{array}{l}\text { Este trabalho teve } \\
\text { como rabjetivo } \\
\text { analisar a eficiência } \\
\text { da Atenção Primária } \\
\text { à Saúde, avaliando } \\
\text { as experiências de } \\
\text { municípios } \\
\text { brasileiros } \\
\text { estado de } r \text { do } \\
\text { Gerais no que se } \\
\text { refere à à rua } \\
\text { eficiência ra na } \\
\text { promoção da saúde. }\end{array}$ & $\begin{array}{l}\text { Entre os principais resultados, } \\
\text { observou-se que as dificuldades } \\
\text { apontadas em comum nos } \\
\text { municípios analisados se } \\
\text { referem à falta de recursos ou } \\
\text { sua limitação, bem como às } \\
\text { condições educacionais da } \\
\text { população e sua baixa } \\
\text { participação e conhecimento } \\
\text { sobre a Estratégia Saúde da } \\
\text { Família. Conclui-se que há } \\
\text { grande necessidade de } \\
\text { trabalhos intersetoriais que } \\
\text { apoiem ações de promoção da } \\
\text { saúde já existentes, bem como } \\
\text { novas estratégias que podem } \\
\text { elevar o nível de conhecimento } \\
\text { da população, dos profissionais } \\
\text { e também dos gestores como } \\
\text { forma de se melhorar o } \\
\text { desempenho da promoção da } \\
\text { saúde. }\end{array}$ \\
\hline
\end{tabular}




\begin{tabular}{|c|c|c|c|c|}
\hline $\begin{array}{c}\text { Atenção Primária à } \\
\text { Saúde na Agenda } \\
\text { Pública Brasileira: } \\
\text { dilemas entre } \\
\text { focalização e } \\
\text { universalidade. } \\
\text { SENNA E SANTOS } \\
\text { (2017) }\end{array}$ & $\begin{array}{l}\text { Revista de } \\
\text { Políticas } \\
\text { Públicas }\end{array}$ & Artigo Revisão & $\begin{array}{ll}\text { Reflexão sobre os } \\
\text { desafios postos à } \\
\text { Atenção } & \text { Primária à } \\
\text { Saúde no } & \text { contexto } \\
\text { brasileiro. }\end{array}$ & $\begin{array}{l}\text { Houve um esforço importante } \\
\text { de expansão da oferta de } \\
\text { serviços de saúde da APS nas } \\
\text { ultimas décadas mas, observa- } \\
\text { se que essa expansão se deu de } \\
\text { forma desigual e heterogênea } \\
\text { no território nacional. As } \\
\text { recentes iniciativas de } \\
\text { constituição das Redes de } \\
\text { Atenção à Saúde confirmam o } \\
\text { ainda frágil desempenho da } \\
\text { APS como eixo organizador da } \\
\text { rede de serviços de saúde e } \\
\text { política universal. Tal } \\
\text { reconhecimento exige } \\
\text { recuperar uma perspectiva } \\
\text { crítica de análise sobre os } \\
\text { constrangimentos que se } \\
\text { impõem ao SUS. }\end{array}$ \\
\hline $\begin{array}{l}\text { Acesso às consultas } \\
\text { médicas nos } \\
\text { serviços públicos de } \\
\text { saúde. } \\
\text { DIAS ET AL (2016) }\end{array}$ & $\begin{array}{c}\text { Revista } \\
\text { Brasileira de } \\
\text { Medicina de } \\
\text { Família e } \\
\text { Comunidade. }\end{array}$ & $\begin{array}{l}\text { Pesquisa } \\
\text { transversal, } \\
\text { analítica de base } \\
\text { populacional, em } \\
\text { município de porte } \\
\text { médio, no estado } \\
\text { de Minas Gerais, } \\
\text { Brasil. Os dados } \\
\text { foram coletados a } \\
\text { partir de } \\
\text { questionário } \\
\text { semiestruturado a } \\
\text { uma amostra } \\
\text { representativa do } \\
\text { município, de } 2150 \\
\text { indivíduos. }\end{array}$ & \begin{tabular}{|lr} 
Avaliar o & acesso às \\
consultas & médicas \\
em & serviços \\
públicos de saúde
\end{tabular} & $\begin{array}{l}\text { 19,4\% afirmou ter procurado } \\
\text { um profissional/serviço } \\
\text { público de saúde nos } 15 \text { dias } \\
\text { anteriores à entrevista. } 75,6 \% \\
\text { foram na APS. A maior procura } \\
\text { foi por parte do sexo feminino } \\
\text { e os sem plano de saúde. A } \\
\text { maioria foi atendida na } \\
\text { primeira vez que procurou o } \\
\text { serviço de saúde pública. Pode- } \\
\text { se destacar uma maior } \\
\text { prevalência ao não acesso } \\
\text { quando a procura foi na APS e } \\
\text { para tratamento/reabilitação. } \\
\text { Utilização de consultas médicas } \\
\text { no ano foi observada para } \\
54,4 \% \text {, com maiores médias } \\
\text { para mulheres, adultos. }\end{array}$ \\
\hline
\end{tabular}

Fonte: Scientific Electronic Library (SCIELO), Literatura Latino-Americana e do Caribe em Ciências da Saúde (LILACS) e Medical Literature Analysis and Retrieval System on-line (MEDLINE) - anos de 2013 a 2017

Sobre "as fragilidades relacionadas ao acesso dos usuários aos serviços de saúde no âmbito da APS" Senna e Santos (2017) discorrem que houve um esforço importante de expansão da oferta de serviços de saúde da APS nas ultimas décadas mas, observa-se que essa expansão se deu de forma desigual e heterogênea no território nacional. As recentes iniciativas de constituição das Redes de Atenção à Saúde confirmam o ainda frágil desempenho da APS como eixo organizador da rede de serviços de saúde e política 
universal. Tal reconhecimento exige recuperar uma perspectiva crítica de análise sobre os constrangimentos que se impõem ao SUS.

As redes de atenção à saúde apresentam três elementos constitutivos: a população, a estrutura operacional e os modelos de atenção à saúde. São consideradas organizações poliárquicas de conjuntos de serviços de saúde, que permitem ofertar uma atenção contínua e integral a determinada população, coordenada pela APS, com responsabilidades sanitária e econômica pela população adscrita e gerando valor para essa população (MENDES, 2011).

Considerando as diferenças locais relacionadas a fatores geográficos Gontijo et al (2017) também conclui que os atributos da APS recebem avaliação heterogênea e a maioria necessita de um olhar mais atento e investimento por parte dos gestores e profissionais. Pôr em prática uma política de saúde mantendo originalmente os princípios e as diretrizes observando as peculiaridades regionais é um grande desafio.

Campos et al (2014) reconhecem a atenção primária como a porta de entrada do sistema de saúde, mas afirmam que o acesso é dificultado por: problemas de organização; uso do acolhimento como barreira ao acesso; falta de recursos humanos; dificuldades em dar seguimento ao tratamento. 0 modelo centrado na doença e a falta de análise crítica podem induzir a descrença nos resultados da atenção primária.

A respeito do uso do acolhimento como barreira ao acesso Coutinho, Barbieri, Santos (2015) expõem que o acolhimento ainda não está totalmente sistematizado nos modelos de atenção à saúde, podendo ser esta uma justificativa para as dificuldades apresentadas tanto por profissionais quanto por usuários. São necessários estudos com novas abordagens ou estratégias para verificar se estas têm reais impacto na qualidade dos serviços e na satisfação dos usuários.

Acerca do atendimento centrado na doença Chagas,Vasconcellos (2013) discorrem que os resultados mostram que o trabalho das equipes de saúde da família no Município de Rio Branco é centrado no médico e no atendimento curativo e que alguns profissionais organizam seu processo de trabalho de forma individual e fragmentada, dificultando o trabalho em equipe.

As repercussões negativas desse tipo de atendimento envolvem: divergências na forma de organização do processo de trabalho, equipes sem planejamento factível, sem responsabilidade coletiva na organização do trabalho. Além do atendimento centrado no 
médico, alguns profissionais organizam seu processo de trabalho de forma individual e fragmentada, dificultando o trabalho em equipe. (CHAGAS,VASCONCELLOS, 2013).

Outra característica identificada como fragilidade por Baratieri et al. (2017) é o descompasso entre a visão médico-centrada e a inadequação das equipes de saúde da APS para atenção à demanda espontânea; acolhimento deficitário na APS gera dificuldades de acesso e baixa resolutividade e desarticulação entre a unidade de pronto atendimento (UPA) e APS.

Oliveira et al (2015) afirma que as Unidades de Pronto Atendimento surgem como uma das estratégias da Política Nacional de Atenção às Urgências para a melhor organização da assistência, articulação dos serviços; e definição de fluxos e referências resolutivas. Criada em 2002, pelo Ministério da Saúde, a proposta baseou-se em experiências de sucesso em cidades como Campinas-SP, Curitiba-PR, Belo Horizonte-MG e Rio de Janeiro-RJ.

Essas unidades devem funcionar 24 horas por dia, prestar atendimento resolutivo aos pacientes acometidos por quadros agudos ou crônicos agudizados, casos de baixa complexidade, à noite e nos finais de semana, quando a rede básica e a Estratégia de Saúde da Família não estão ativas. Devem construir fluxos coerentes e efetivos de referência e contrarreferência com outras instituições e serviços de saúde do sistema locorregional. (OLIVEIRA, ET AL, 2015).

A necessidade de estruturação da coordenação do cuidado, conclui que as UPA's são vistas pela população como mais resolutivas, havendo necessidade de ordenar fluxos de atendimento e educar/informar a população sobre seu funcionamento.

Almeida e Santos (2016) também identificaram que a função de porta de entrada preferencial pela APS deparou-se com forte concorrência de serviços ambulatoriais hospitalares e de pronto-atendimento, desarticulados da rede. Problemas de acesso e oferta de atenção especializada eram agravados pela dependência do setor privado nas regiões, ainda que tenham sido observados avanços na institucionalização de fluxos desde a Atenção Primária à Saúde. A contrarreferência era deficiente e a comunicação interprofissional escassa.

Sobre o sistema de referência e contrarreferência, caracteriza-se por uma tentativa de organizar os serviços de saúde, a medida que o usuário necessite de um atendimento de maior complexidade. Diz-se então, que o individuo será "referenciado" (encaminhado). 
Quando concluído o atendimento dessa necessidade especial, o mesmo deve ser "contrarreferenciado", ou seja, o profissional deve encaminhar o usuário para a unidade de origem para que haja continuidade do atendimento. (ALVES et al, 2015)

Dias et al (2016) procurou avaliar o acesso às consultas médicas em serviços públicos de saúde e identificou em sua pesquisa que 19,4\% afirmou ter procurado um profissional/serviço público de saúde nos 15 dias anteriores à entrevista. 75,6\% foram na APS. A maior procura foi por parte do sexo feminino e os sem plano de saúde. A maioria foi atendida na primeira vez que procurou o serviço de saúde pública. Pode-se destacar uma maior prevalência ao não acesso quando a procura foi na APS e para tratamento/reabilitação. Utilização de consultas médicas no ano foi observada para 54,4\%, com maiores médias para mulheres, adultos e sem plano de saúde.

É importante salientar a existência de diferenças de fragilidades quando analisadas o atendimento da ESF e da UBS tradicional sobre isto, Marin, Marchioli, Moracvick (2013) expõem que as fragilidades e as fortalezas das duas modalidades assemelham-se quanto ao acesso, porta de entrada, oferta de serviços de saúde de diferentes níveis de densidade tecnológica e sua articulação. Para os usuários da ESF, o vínculo, a longitudinalidade e o enfoque familiar ocorrem de forma mais efetiva. Quanto à equipe profissional, os usuários da UBS tradicional demonstram maior satisfação. Para os usuários da ESF, ao se disponibilizar apenas médico generalista, não se atende a todas as necessidades. Há necessidade de ajustes nas duas modalidades.

Cabral et al (2016) observaram que as dificuldades apontadas em comum nos municípios analisados se referem à falta de recursos ou sua limitação, bem como às condições educacionais da população e sua baixa participação e conhecimento sobre a Estratégia Saúde da Família. Conclui-se que há grande necessidade de trabalhos intersetoriais que apoiem ações de promoção da saúde já existentes, bem como novas estratégias que podem elevar o nível de conhecimento da população, dos profissionais e também dos gestores como forma de se melhorar o desempenho da promoção da saúde.

\section{Categoria 3: A importância da atenção primária enquanto porta de entrada dos usuários na rede dos serviços de saúde}

Esta categoria foi abordada por 6 (seis) estudos, correspondendo à 26,08\% do total, sendo estes destacados no quadro 3. 
Quadro 3 - Caracterização dos estudos sobre "A importância da atenção primária enquanto porta de entrada dos usuários na rede dos serviços de saúde"

\begin{tabular}{|c|c|c|c|c|}
\hline $\begin{array}{c}\text { ARTIGOS/ } \\
\text { AUTORES/ANO }\end{array}$ & $\begin{array}{c}\text { PERIÓDIC } \\
0\end{array}$ & $\begin{array}{c}\text { TIPO DE } \\
\text { PESQUISA }\end{array}$ & OBJETIVO & RESULTADO \\
\hline $\begin{array}{l}\text { Aposição da } \\
\text { estratégia saúde da } \\
\text { família na rede de } \\
\text { atenção à saúde na } \\
\text { perspectiva das } \\
\text { equipes e usuários } \\
\text { participantes do } \\
\text { programa nacional } \\
\text { para melhoria do } \\
\text { acesso e da qualidade } \\
\text { da atenção básica. } \\
\text { FAUSTO et al (2014) }\end{array}$ & $\begin{array}{l}\text { Saúde } \\
\text { Debate }\end{array}$ & $\begin{array}{l}\text { Estudo } \\
\text { transversal, } \\
\text { cujas } \\
\text { informações } \\
\text { foram geradas a } \\
\text { partir do banco } \\
\text { de dados de base } \\
\text { nacional da } \\
\text { avaliação } \\
\text { externa } \\
\text { PMAQ-AB. do } \\
\end{array}$ & $\begin{array}{l}\text { Analisar a posição da } \\
\text { Estratégia Saúde da } \\
\text { Família na rede de } \\
\text { atenção à saúde sob a } \\
\text { perspectiva das } \\
\text { equipes de Saúde da } \\
\text { Família e dos } \\
\text { usuários } \\
\text { participantes do } \\
\text { Programa Nacional } \\
\text { para Melhoria do } \\
\text { Acesso e da } \\
\text { Qualidade da Atenção } \\
\text { Básica. }\end{array}$ & $\begin{array}{l}\text { Os resultados indicam que as equipes } \\
\text { atuam cada vez mais como porta de } \\
\text { entrada preferencial, atendendo a } \\
\text { demandas diversas e exercendo a } \\
\text { função de filtro para a atenção } \\
\text { especializada. Contudo, persistem } \\
\text { importantes } \\
\text { organizacionais para acesso, os fluxos } \\
\text { estão pouco ordenados, a integração } \\
\text { da APS à rede ainda é incipiente e } \\
\text { inexiste coordenação entre APS e } \\
\text { atenção especializada. }\end{array}$ \\
\hline \begin{tabular}{|c|} 
Práticas do \\
enfermeiro no \\
contexto da atenção \\
básica: artigo de \\
revisão. \\
BARBIANI, NORA, \\
SCHAEFER (2016)
\end{tabular} & \begin{tabular}{|} 
Revista \\
Latino- \\
American \\
a de \\
Enfermag \\
em
\end{tabular} & $\begin{array}{l}\text { Revisão da } \\
\text { literatura com o } \\
\text { método scoping } \\
\text { review, nas bases } \\
\text { LILACS, IBECS, } \\
\text { BDENF, CINAHL } \\
\text { e MEDLINE, e nas } \\
\text { bibliotecas } \\
\text { Cochrane e } \\
\text { SciELO. }\end{array}$ & $\begin{array}{l}\text { Identificar } \\
\text { categorizar } \\
\text { práticas exercidas } \\
\text { pelos enfermeiros } \\
\text { junto às Unidades } \\
\text { Básicas e às Equipes } \\
\text { de Saúde da Família, } \\
\text { à luz das atribuições } \\
\text { previstas pelos } \\
\text { marcos legais e } \\
\text { programáticos da } \\
\text { profissão e do SUS. }\end{array}$ & $\begin{array}{l}\text { os desafios dos enfermeiros são } \\
\text { complexos, posto que o cuidado deve } \\
\text { estar centrado nas necessidades de } \\
\text { saúde da população, o que remete à } \\
\text { ação para outros níveis de } \\
\text { responsabilidade clínica e sanitária. A } \\
\text { enfermagem brasileira mostra } \\
\text { importantes avanços desde a } \\
\text { implantação das políticas de } \\
\text { reorganização do trabalho. Necessita, } \\
\text { entretanto, avançar no que se refere } \\
\text { ao deslocamento dos processos de } \\
\text { trabalho, focados em procedimentos } \\
\text { individuais, para um processo mais } \\
\text { voltado aos usuários, onde a clínica } \\
\text { ampliada seja o imperativo ético- } \\
\text { político da organização dos serviços e } \\
\text { da intervenção profissional. }\end{array}$ \\
\hline $\begin{array}{c}\text { A qualidade da } \\
\text { atenção primária no } \\
\text { programa mais } \\
\text { médicos- a } \\
\text { expêriencia dos } \\
\text { médicos e usuários. } \\
\text { OPAS (2017) }\end{array}$ & $\begin{array}{c}\text { Biblioteca } \\
\text { Virtual } \\
\text { da Saúde } \\
\text { (BVS) }\end{array}$ & $\begin{array}{l}\text { Trata-se de um } \\
\text { estudo } \\
\text { transversal de } \\
\text { abrangência } \\
\text { Nacional com } \\
\text { amostra ra de } \\
\text { usuários adultos } \\
\text { das UBS com } \\
\text { equipes do ESF } \\
\text { de todas as } \\
\text { regiões do Brasil. }\end{array}$ & $\begin{array}{l}\text { Avaliar a força da } \\
\text { APS à saúde nas } \\
\text { equipes } \\
\text { estratégias saúde das } \\
\text { família de todo Brasil, } \\
\text { por meio da } \\
\text { experiência r de } \\
\text { usuários dos serviços } \\
\text { e de médicos cubanos } \\
\text { participantes do } \\
\text { programa r mais } \\
\text { médicos. }\end{array}$ & $\begin{array}{l}\text { As estratégias nacionais para } \\
\text { ampliação e qualificação da APS no } \\
\text { Brasil têm feito escores mais altos na } \\
\text { maioria das regiões, apesar da } \\
\text { dificuldade de acesso às Unidades de } \\
\text { Saúde da Família, aqueles pacientes } \\
\text { que conseguem acessá-las } \\
\text { desenvolvem relações de confiança } \\
\text { com os médicos, como demonstram } \\
\text { os Escores de Longitudinalidade. }\end{array}$ \\
\hline
\end{tabular}




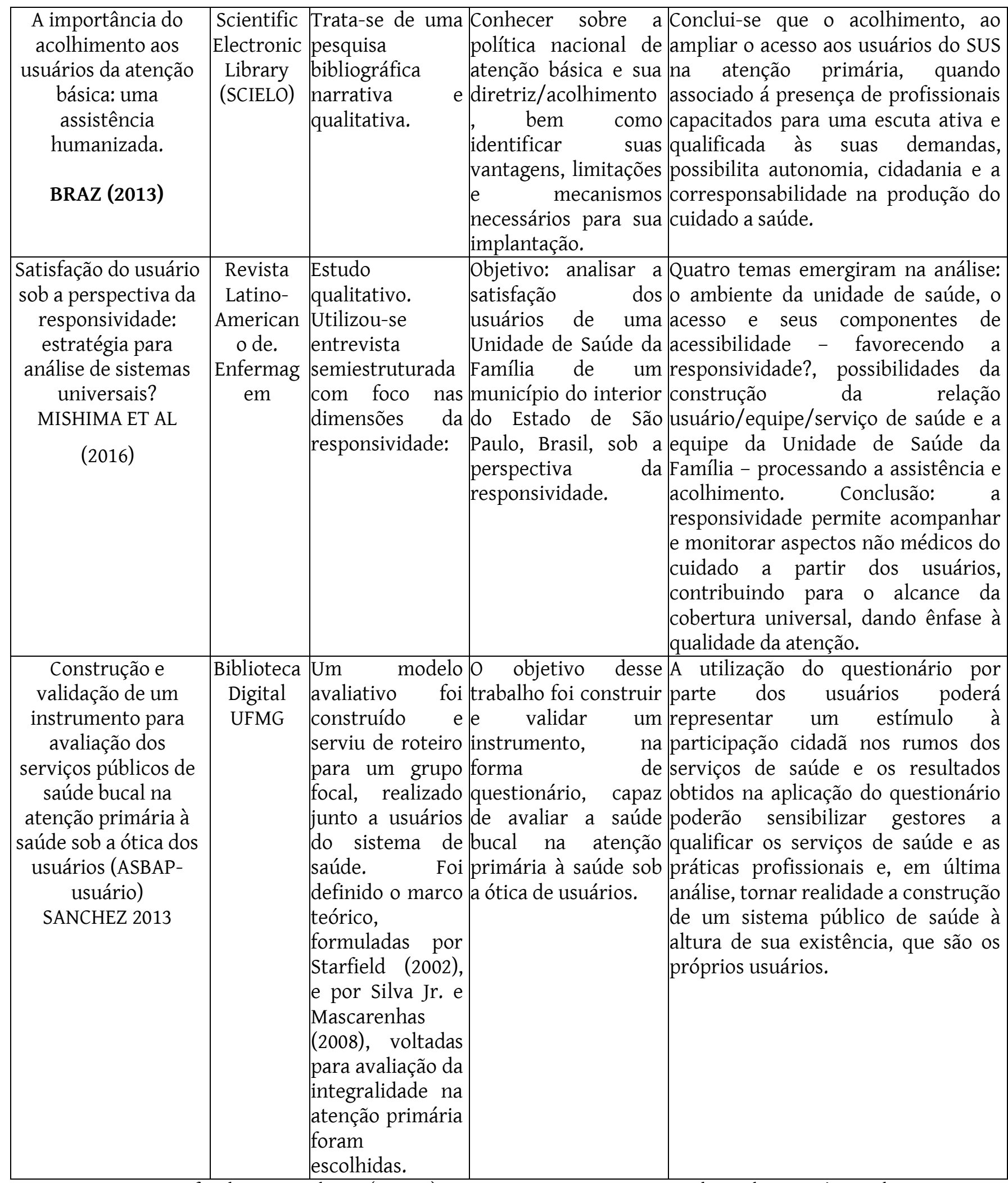

Fonte: Scientific Electronic Library (SCIELO), Literatura Latino-Americana e do Caribe em Ciências da Saúde (LILACS) e Medical Literature Analysis and Retrieval System on-line (MEDLINE) - anos de 2013 a 2017.

Em relação a categoria “a importância da atenção primária enquanto porta de entrada dos usuários na rede dos serviços de saúde" Fausto et al (2014) afirma queos 
resultados indicam que as equipes atuam cada vez mais como porta de entrada preferencial, atendendo a demandas diversas e exercendo a função de filtro para a atenção especializada. Contudo, persistem importantes barreiras organizacionais para acesso, os fluxos estão pouco ordenados, a integração da APS à rede ainda é incipiente e inexiste coordenação entre APS e atenção especializada.

Com o objetivo de avaliar a força da APS à saúde nas equipes das estratégias saúde da família de todo Brasil, através de estratégias nacionais para ampliação e qualificação da APS, OPAS (2018) evidenciaram que no Brasil tais estratégias têm feito escores mais altos na maioria das regiões, apesar da dificuldade de acesso às Unidades de Saúde da Família, aqueles pacientes que conseguem acessá-las desenvolvem relações de confiança com os médicos.

Para BRAZ (2013) o acolhimento, ao ampliar o acesso aos usuários do SUS na atenção primária, quando associado a presença de profissionais capacitados para uma escuta ativa e qualificada às suas demandas, permite atender aos princípios da humanização.

Considerando a importância especificamente da atuação do Enfermeiro no contexto da atenção básica Barbiani, Nora, Schaefer (2016) diz que os desafios dos enfermeiros são complexos, posto que o cuidado deve estar centrado nas necessidades de saúde da população, o que remete à ação para outros níveis de responsabilidade clínica e sanitária.

A enfermagem brasileira mostra importantes avanços desde a implantação das políticas de reorganização do trabalho. Entretanto, necessita avançar no que se refere ao deslocamento dos processos de trabalho, focados em procedimentos individuais, para um processo mais voltado aos usuários, onde a clínica ampliada seja o imperativo ético-político da organização dos serviços e da intervenção profissional. (BARBIANI, NORA, SCHAEFER, 2016)

A clínica ampliada e compartilhada, vem com a proposta de entender o significado do adoecimento e tratar a doença no contexto de vida, no qual esta doença está inserida. Portanto, sua proposta, não é tratar a doença, mas o sujeito de maneira integral. (SAMPAIO, 2014)

Sanchez (2013) destaca a importância da utilização de questionário por parte dos usuários na avaliação dos serviços de saúde, representando um estímulo à participação 
cidadã nos rumos dos serviços de saúde e os resultados obtidos na aplicação do questionário poderão sensibilizar gestores a qualificar os serviços de saúde e as práticas profissionais.

É fato que o sucesso da APS como porta de atenção primária na rede dos serviços de saúde e centro de comunicação da RAS, coordenadora do cuidado e ordenadora das ações e serviços disponibilizados na rede, depende de vários fatores, tais como, estrutura organizada, introdução de novas práticas, novos instrumentos de gestão, de forma integrada, eficiente e efetiva.

\section{CONSIDERAÇÕES FINAIS}

A organização da porta de entrada é um dos elementos essenciais para potencializar a APS como coordenadora do cuidado e ordenadora das redes de atenção à saúde. Está composta pelo seguinte conjunto de indicadores: acolhimento, atendimento à demanda espontânea e atendimento de urgência e emergência.

É de extrema relevância empreender uma discussão mais sólida sobre as diferentes formas de acesso aos usuários da APS e também vislumbrar ações de melhoria tanto no planejamento quanto nas relações entre todos os integrantes da equipe de saúde e dos usuários que buscam atendimento no sistema único de saúde.

Neste sentido o acesso estaria ligado à obtenção de determinado tipo de ação que seja resolutiva para o tipo de problema de saúde do usuário. Um dos fatores limitantes discutidos no estudo foram as dificuldades para marcação de consultas com alguns especialistas e a demora na realização de alguns exames de laboratório, falta de medicamentos, poucas consultas. Isso gera uma descrença no papel ordenador da APS e acabam servindo como álibi para as tentativas de deslocar a APS como porta de entrada do SUS.

No entanto, foi possível perceber, através da literatura pesquisada, que é possível a implantação efetiva da rede de atenção á saúde nos municípios brasileiros. É um caminho a ser construído por gestores e profissionais de saúde, com o apoio da comunidade. Uma vez que a legislação brasileira preconiza que os usuários precisam ter garantido o acesso a todos os serviços de saúde, essenciais para a qualidade de vida, assim como ter garantido a resolutividade dos problemas de saúde, possibilitando dessa forma a integralidade dos cuidados. 
Destaca-se ainda que no âmbito da saúde, assim como os usuários enfrentam as mais diversas situações, problemas e aflições, os profissionais que vivenciam a prática na atenção básica, também possuem interfaces que são permeadas por barreiras geográficas, carência de recursos humanos, materiais e tecnológicos, dificuldades essas vivenciadas nas suas rotinas laborais.

As concepções dos usuários do SUS com relação à atenção primária demonstraram muitas fragilidades quanto ao modo de ver as ações que são desenvolvidas pelo sistema. Nem sempre condizem com a realidade teórica e com a prática vivenciada diariamente. Nota-se, através doa achados bibliográficos, que os usuários do sistema conseguem perceber as potencialidades e fragilidades na atenção primária à saúde, no entanto apenas a identificação não garante melhorias. É necessário articular o fortalecimento das potencialidades e corrigir as fragilidades para o efetivo sucesso da política de saúde.

Dessa maneira, foi possível atender aos objetivos da pesquisa e assim, pode-se propor com o estudo medidas que evidenciem a importância das equipes de estratégia saúde da família, como um modelo de reorientação da atenção a saúde em nosso país, pois há muito que fazer, transformar e aperfeiçoar os atendimento.

Com isso, a população ao ter profissionais de saúde capacitados mais próximos de sua residência tem garantido os princípios organizativos e doutrinários do SUS, com uma rede de serviços e sistemas integrados de saúde, além de um atendimento humanizado, satisfazendo os usuários que buscam a tão sonhada qualidade dos serviços públicos.

\section{REFERÊNCIAS}

ALMEIDA, PF; MARIN, J; CASOTTI, E. Estratégias para Consolidação da Coordenação do Cuidado pela Atenção Básica. Trabalho. Educação. Saúde. 2017, vol.15, n.2, pp.373-398. Epub Mar 13, 2017. Disponível em: <http://dx.doi.org/10.1590/1981-7746-solo0064>. Acesso em: 08 fev 2018

ALMEIDA, PF; SANTOS, AM. Atenção Primária à Saúde: coordenadora do cuidado em redes regionalizadas? Revista de Saúde Pública. 50:80, 2016. Disponível em: <http://www.scielo.br/pdf/rsp/v50/pt_0034-8910-rspS1518-87872016050006602.pdf>. Acesso em: 10 março 2018

Alves, M.L.F. Guedes, H.M. Martins, J.C.A. Chianca, T.C.M. Rede de referência e contrarreferência para o atendimento de urgências em um município do interior de Minas Gerais - Brasil. Rev Med Minas Gerais 2015; 25(4): 469-475

ARANTES, LJ; SHIMIZU, HE; HAMANN, E. Contribuições e desafios da Estratégia Saúde da Família na Atenção Primária à Saúde no Brasil: revisão da literatura. Ciências Saúde Coletiva. 2016, vol.21, n.5, pp.1499-1510. Disponível em: <http://dx.doi.org/10.1590/1413-81232015215.19602015> Acesso em: 20 março 2018 
ARANTES, LJ; SHIMIZU, HE; HAMANN, EM. Contribuições e desafios da Estratégia Saúde da Família na Atenção Primária à Saúde no Brasil: revisão da literatura. Ciência e Saúde Coletiva, 21(5):1499-1509, 2016. Disponível em: <http://www.scielo.br/pdf/csc/v21n5/1413-8123-csc-21-05-1499.pdf>. Acesso em: 15 abril 2018

BARATIERI et al. Percepções de usuários atendidos em um Pronto Atendimento: olhar sobre a Atenção Primária à Saúde. V. 18; n. 01, 2017. Disponível em: <http://www.uel.br/revistas/uel/index.php/espacoparasaude/article/view/28351>. Acesso em: 05 abril 2018

BARBIANI, R; NORA CRD; SCHAEFER, R. Práticas do enfermeiro no contexto da atenção básica. Artigo de Revisão. Revista Latino-Americana de Enfermagem. 2016; 24:e2721. Disponível em: $<$ http://dx.doi.org/10.1590/1518-8345.0880.2721>. Acesso em: 01 maio 2018

BRASIL. Conselho Nacional de Secretários de Saúde. Atenção Primária

Brasília: CONASS, 2011. Disponível em: <https://www.passeidireto.com/arquivo/ 6468505/atencao-primaria-eatencao-a-saude>. Acesso em: 27 março 2018

BRASIL. Ministério da Saúde. PORTARIA № 2.436, DE 21 DE SETEMBRO DE 2017. Brasília-DF, 2017. Disponível em: <http://www.foa.unesp.br/home/pos/ppgops/portaria-n-2436.pdf>. Acesso em: 22 abril 2018

BRAZ, FAF. A importância do acolhimento aos usuários da atenção básica: uma assistência humanizada. Trabalho de Conclusão de Curso. Especialização em Atenção Básica em Saúde da Família. Universidade Federal de Minas Gerais. Campos Gerais/Minas Gerais. 2013. Disponível em: <https://www.nescon.medicina.ufmg.br/biblioteca/imagem/4179.pdf>. Acesso em: 13 maio 2018

BRUNHAUSER, AL; MAGRO, ML; NEVES, M.Avaliação de serviços de saúde bucal: um estudo comparativo. Revista da faculdade de odontologia Universidade de Passo Fundo. V.18, n. 1, 2013. Disponível em: <http://seer.upf.br/index.php/rfo/article/ view/2850.> Acesso em: 22 maio 2018

Bonello AADLM, Corrêa CRS. Acesso aos serviços básicos de saúde e fatores associados: estudo de base populacional. Revista Ciência \& Saúde Coletiva, 19(11):4397-4406, 2014

CABRAL, KFD; ET AL. Análise da Eficiência na Atenção Primária à Saúde sob a Ótica dos Profissionais da Área. Revista de Gestão em Sistemas de Saúde, v. 5, n. 2, p. 71-83, 2016. Disponível em: $<$ http://www.spell.org.br/documentos/ver/44382/ analise-da-eficiencia-na-atencao-primaria-a-saude-sob-aotica-dos-profissionais-da-area>. Acesso em: 15 maio 2018

CAMPOS, RTO; ET AL. Avaliação da qualidade do acesso na atenção primária de uma grande cidade brasileira na perspectiva dos usuários. Saúde Debate. 2014, vol.38, n.spe, pp.252-264. Disponível em: <http://dx.doi.org/10.5935/0103-1104.2014S019>. Acesso em: 09 março 2018.

CHAGAS, HMA; VASCONCELLOS, MPC. Quando a porta de entrada não resolve: análise das unidades de saúde da família no município de Rio Branco, Acre. Saúde e Sociedade. 2013, vol.22, n.2, pp.377-388. Disponível em: <http://dx.doi.org/10.1590/S0104-12902013000200010>. Acesso em: 03 maio 2018.

CMM, SENNA; SANTOS, AM. Atenção Primária à Saúde Na Agenda Pública Brasileira: Dilemas Entre Focalização e Universalidade Revista de Políticas Públicas, vol. 21, núm. 1, 2017, pp. 403-424 Universidade Federal do Maranhão São Luís, Brasil. Disponível em: <http://www.redalyc.org/pdf/3211/321152454021.pdf>. Acesso em: 01 junho 2018

COUTINHO, LRP; BARBIERI, AR; SANTOS, MLM. Acolhimento na Atenção Primária à Saúde: revisão integrativa. Saúde Debate. 2015, vol.39, n.105, pp.514-524. Disponível em: <http://dx.doi.org/10.1590/0103$110420151050002018>$ Acesso em: 01 junho 2018.

DEMARZO, MMP. Módulo Político Gestor. Reorganização dos Sistemas de Saúde: Promoção da Saúde e Atenção Primária à Saúde. Especialização em Saúde da Família. Modalidade à distância. Universidade Federal de São Paulo. Universidade Aberta do SUS. 2011. Disponível em: $<$ http://www.unasus.unifesp.br/biblioteca_virtual/esf/1/ modulo_politico_gestor/Unidade_3.pdf>. Acesso em: 23 março 2018. 
DIAS, OV; et al. Acesso às consultas médicas nos serviços públicos de saúde. Revista Brasileira de Medicina de Família e Comunidade. v.11, n. 38, 2016. Disponível em: <https://www.rbmfc.org.br/rbmfc/article/view/1185>. Acesso em: 17 abril 2018.

FAUSTO, MCR et al. A posição da Estratégia Saúde da Família na rede de atenção à saúde na perspectiva das equipes e usuários participantes do PMAQ-AB. Saúde Debate 2014, vol.38, n.spe, pp.13-33. Disponível em: <http://dx.doi.org/10.5935/0103-1104.2014S003> Acesso em: 30 abril 2018.

GONTIJO, TL; et al. Avaliação da atenção primária: o ponto de vista de usuários. Saúde Debate 2017, vol.41, n.114, pp.741-752. Disponível em: <http://dx.doi.org/10.1590/0103-1104201711406>. Acesso em:11 abril 2018.

MARIN, MJS; MARCHIOLI, M; MORACVICK, MYAD. Fortalezas e fragilidades do atendimento nas Unidades Básicas de Saúde tradicionais e da Estratégia de Saúde da Família pela ótica dos usuários. Texto Contexto Enfermagem. 2013, vol.22, n.3, pp.780-788. Disponível em: <http://dx.doi.org/10.1590/S010407072013000300026> Acesso em:09 maio 2018.

MELLO, GA; FONTANELlA, BJB; DEMARZO, MMP. Atenção Básica e Atenção Primária á Saúde - Origens e Diferenças Conceituais. Artigo de Revisão. Revista Atenção Primária à Saúde. v. 12, n. 2, p. 204-213, abr./jun. 2009 Disponível em: <https://aps.ufjf.emnuvens.com.br/aps/article/view/307/203>. Acesso em: 19 maio 2018.

MENDES, E.V. As redes de atenção à saúde. Brasília: Organização Pan-

-Americana da Saúde, 2011.

MENDES, E.V. A Construção Social da Atenção Primária À Saúde. Brasília: Conselho Nacional de Secretários de Saúde - CONASS, 2015. Disponível em: <http://www.saude.go. gov.br/wp-content/uploads/2016/12/aconstrucao-social-da-atencao-primaria-a-saude.pdf>. Acesso em: 05 maio 2018.

MISHIMA, SM, et al. Satisfação do usuário sob a perspectiva da responsividade: estratégia para análise de sistemas universais?. Revista. Latino-Americana de Enfermagem. 2016; 24:e2674.Disponível em: <http://dx.doi.org/10.1590/ 1518-8345.1089.2674>. Acesso em: 02 junho 2018.

OLIVEIRA, MAC; PEREIRA, IC. Atributos essenciais da Atenção Primária e a Estratégia Saúde da Família Revista. Brasileira de Enfermagem. 2013, vol.66, n.spe, pp.158-164. Disponível em: <http://dx.doi.org/10.1590/S003471672013000700020>. Acesso em: 02 junho 2018.

Oliveira SN, Ramos BJ, Piazza M, Prado ML, Reibnitz KS, Souza AC. Unidade de Pronto Atendimento - UPA

24h: Percepção da Enfermagem. Texto Contexto Enferm, Florianópolis, 2015 Jan-Mar; 24(1): 238-44

Organização Mundial de Saúde (OMS). Declaração de Alma-Ata. Conferência Internacional sobre Cuidados Primários de Saúde Alma-Ata URSS, 6-12 de setembro de 1978. Disponível em: <http://cmdss2011.org/ site/wp-content/uploads/2011/07/Declara \%C3\%A7\%C3\%A3o-Alma-Ata.pdf>. Acesso em: 02 junho 2018.

Organização Pan-Americana da Saúde. OPAS. Qualidade da atenção primária no Programa Mais Médicos. A experiência dos médicos e usuários. Brasília, D.F.: OPAS; 2018. Disponível em: <http://iris.paho.org/xmlui/bitstream/handle/123456789/34573/ $\quad$ OPASBRA18004por.pdf?sequence=1\&isAllowed=y>. Acesso em: 11 maio 2018 .

PRODANOV, CC; FREITAS, EC. Metodologia do trabalho científico :métodos e técnicas da pesquisa e do trabalho acadêmico. 2. ed. Novo Hamburgo: Feevale, 2013. Disponível em: <http://www.feevale.br/Comum/midias/8807f05a-14d0-4d5b-b1ad-1538f3aef538/Ebook\%20Metodologia\%20do\%20Trabalho\%20Cientifico.pdf>. Acesso em: 07 maio 2018

PROTASIO, APL; et al. Satisfação do usuário da Atenção Básica em Saúde por regiões do Brasil: 1ำ ciclo de avaliação externa do PMAQ-AB. Ciência Saúde Coletiva. 2017, vol.22, n.6, pp.1829-1844. Disponível em: <http://dx.doi.org/10.1590/ 1413-81232017226.26472015>. Acesso em: 08 maio 2018.

SAMPAIO , R.C. Clínica Ampliada e Compartilhada. 2014. Disponível em: http://redehumanizasus.net/85422-clinica-ampliada-e-compartilhada/ 
SANCHEZ, HF .Construção e validação de um instrumento para avaliação dos serviços públicos de saúde bucal na atenção primária à saúde sob a ótica dos usuários (ASBAP-usuário). 2013. Disponível em: <http://www.bibliotecadigital.ufmg.br/dspace/handle/ 1843/ZMRO-9D2NAX>. Acesso em: 08 maio 2018.

SANTOS, FPA; et al. Práticas de cuidado da enfermeira na Estratégia Saúde da Família. Revista Brasileira de Enfermagem. 2016, vol.69, n.6, pp.1124-1131. Disponível em: <http://dx.doi.org/10.1590/0034-7167-20160273> Aceso em: 08 maio 2018.

Starfield, B. Atenção Primária: equilíbrio entre necessidades de saúde, serviços e tecnologia. Brasília: UNESCO. Ministério da Saúde, $2002 . \quad$ Disponível em: <http://bvsms.saude.gov.br/bvs/publicacoes/atencao_primaria_p1.pdf>. Acesso em: 15 março 2018.

VOLPONI, PRR; GARANHANI, ML; CARVALHO, BG. Núcleo de Apoio à Saúde da Família: potencialidades como dispositivo de mudança na Atenção Básica em saúde. Saúde Debate 2015, vol.39, n.spe, pp.221-231. Disponível em: <http://dx.doi.org/10.5935/0103-1104.2015S005418>Acesso: maio 2018.

(cc) EY

Este trabalho está licenciado com uma Licença Creative Commons - Atribuição 4.0 Internacional. 